\title{
Socio-Economic, Cultural and Family Factors Causing Juvenile Delinquency and Its Consequences in Bangladesh: A Look for Way Out
}

\author{
Md. Manjur Hossain Patoari
}

Assistant Professor Department of Law International Islamic University Chittagong, Bangladesh. Email:manjuiiucs@yahoo.com

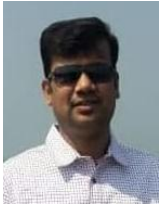

\begin{abstract}
One of the most severe problems irritating current societies in different countries of the world is juvenile delinquency. Juvenile delinquency is a social disease for any country and the problem is more horrendous in Bangladesh. It is very much alarming for any country as it ruin the life of the youth generation of a country. As a poor and densely populated country of the third world it is very disastrous for Bangladesh as it has direct effects not only on the victim of the crime but also on their family, society and country. Like many other countries of the world the trend of juvenile delinquency is rapidly increasing in Bangladesh. Due to various socio-economic, cultural and family factors both boys and girls of teenagers in Bangladesh are getting involved in different types of anti-social activities like drug addiction, drug trafficking, eve-teasing, sexual offences, extortion, swipe, smuggling, criminalized politics and sometimes even involved in murder and several others felonious actions. The main object of this study is to explore the different socioeconomic, cultural and family factors that cause juvenile delinquency in Bangladesh and its impacts on the family, society and country and also to provide an avenue to eliminate juvenile delinquency in Bangladesh. This study is basically qualitative in nature where data have been collected from secondary source only. For collecting data various national and international journals, books, news paper writing etc. are analyzed.
\end{abstract}

Keywords: Juvenile delinquency, Socio-economic factors, Cultural factors, Family factors, Juvenile justice.

JEL Classification: I25, I28, I30, J12, J13, K14.

Citation | Md. Manjur Hossain Patoari (2020). Socio-Economic, Cultural and Family Factors Causing Juvenile Delinquency and Its Consequences in Bangladesh: A Look for Way Out. Asian Journal of Social Sciences and Management Studies, 7(2): 89-98. History:

Received: 30 January 2020

Revised: 11 March 2020

Accepted: 15 April 2020

Published: 8 May 2020

Licensed: This work is licensed under a Creative Commons

Attribution 3.0 License (c)

Publisher: Asian Online Journal Publishing Group
Funding: This study received no specific financial support.

Competing Interests: The author declares that there are no conflicts of interests regarding the publication of this paper.

Transparency: The author confirms that the manuscript is an honest, accurate, and transparent account of the study was reported; that no vital features of the study have been omitted; and that any discrepancies from the features of the study have been omitted;
study as planned have been explained.

Ethical: This study follows all ethical practices during writing.

\section{Contents}

1. Introduction.

2. Meaning of Juvenile Delinquency ........... 90

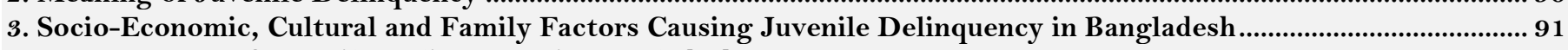

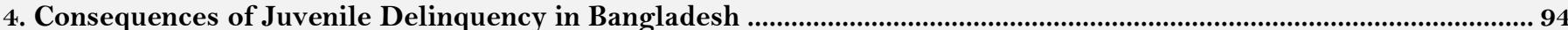

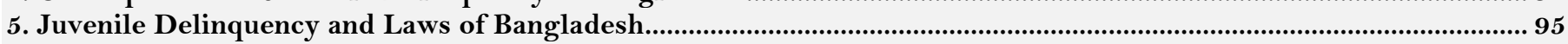

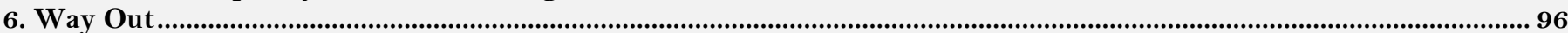

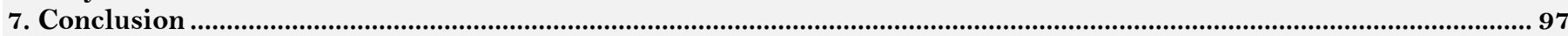

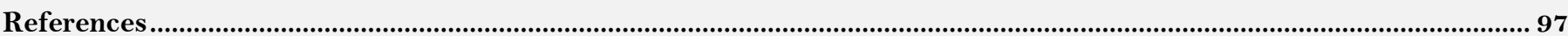




\section{Contribution of this paper to the literature}

This paper makes a unique contribution to the literature of juvenile delinquency in Bangladesh. It traces out various factors causing juvenile delinquency in Bangladesh and also provides an avenue to eradicate juvenile delinquency in Bangladesh.

\section{Introduction}

Today's children are the future leader of a nation. The future development, progress and prosperity of a nation depend on her children. To achieve future goal, a nation must be concern about the life of her youth generation. One of the most important objects of a country is her children who will lead the nation in future. If a nation cannot convert her children into human resources in true sense by proper care, guidance, education and proper technical training, the real development of that nation in future in any sector is quite impossible. Juvenility is an important transitional period of development from infancy to majority as during this period biological as well as emotional changes take place in the life of a child. To involve juvenile in the formation of the nation the first condition is that juvenile must be free from crime. To build the life of a child family is the first and primary institution which has tremendous ascendency on child. By proper care, guidance and teaching family especially the parents can play a vital role in the physical, mental, social, cultural, ethical and spiritual development of a child. Due to rapid revolutionary biological as well as emotional changes the period of juvenility is full of anxieties, worries, variances and complications and as their mental faculties are not mature enough cannot take the right decision in life and frequently involve in anti-social activities and become delinquent. "A delinquent young person is disobedient and wayward, runs away from home and school, cannot be controlled by parents and teachers, is not amenable to any kind of discipline, is self-willed and habitually acts in a manner injurious to the welfare and happiness of others and himself" (Rathinabalan \& Naaraayan, 2017). As parent's life style, practices and teaching has direct impact on the life of the children (Hoeve et al., 2009) proper education, teaching, guidance and care of the family can play an exigent role in the physical and mental development of a children. Beside these, socio-economic, cultural, political situation, environment, law and order situation of the country has impact on the nature and behaviors of the people of the country especially on teenagers. Naturally with increasing the age the mental faculties of the juveniles mature gradually and acquire decision making ability regarding various issues relating to their life like social, economical, educational, cultural and political but difficulties arise when they involve in any kind of antisocial activity due to various reasons. Crime and age are closely connected as rate of criminality is high among the juveniles and falls with increasing age (Ahmad, 2017).

One of the major disasters of society occurs when adolescents involve in social disorderliness in any ways other than social norms and values (Mehtab, 2008). Due to variation of social, economical, cultural, educational, religious teaching, family conflict, law and order situation of the country, environment and political situation the rate of juvenile delinquency is different from state to state. Bangladesh as one of the densely populated countries of the world, juvenile delinquency rate is normally higher than many countries. Day by day women are being involved in economic activities more and most of the time of the day they have to stay outside of the house as a result a mother being the primary and best teacher of her children cannot play remarkable role in the physical and mental development of the children. Moreover, due to urbanization and industrialization day by day the rate of juvenile delinquency is increasing rapidly in the country (Mehtab, 2008) which deviate the attention of the youth generation of the country from their main task i.e. education, healthcare, sports, cultural activities, religious teaching, social and humanitarian activities. Delinquent juveniles involves themselves more in antisocial activities than positive actions which destroy their prospective career and that have pushed them into darkness in there exists (Alamgir, Rahim, \& Ali, 2018). Juveniles are the most sensitive section of a country and their response towards any antisocial activities is very fast and sometimes due to more pressure and try to extra control the juveniles lead them to get involved themselves in culpable actions (Chowdhury, Khan, \& Uddin, 2012). As one of the root causes of adult criminality is juvenile delinquency, it is a matter of great concern for Bangladesh because at present approximately 40 million children in Bangladesh age 5 to 17 years and among them almost 550,000 are drug addicted (Noman, 2018) and some of them are involved in picketing, drug trafficking, arms trafficking, human trafficking, eve-teasing and other petty criminal activities. Some of them are involve more heinous offences like sexual violence, political violence, extortion, robbery, kidnapping, acid throwing and murder. Children from poor families as well as rich and aristocratic families are involved in criminal activities (Chowdhury. \& Fahim, 2019). According to the Constitution of the Peoples' Republic of Bangladesh it is the duty of the state to adopt appropriate measures for the protection of the women, children and backward section of the country. The government of Bangladesh especially through the Ministry of Social Welfare performing various functions to ensure adequate protection of the juveniles and also to refrains from doing antisocial activities. To fulfill the mandate of the constitution and the United Nations Convention on the Rights of the Children, 1989 and also to fulfill the directions of the apex court given in the cases of The State vs The Secretary, Ministry of Law, Justice and Parliamentary Affairs 59 DLR 72 (2007) and The State vs The Secretary, Ministry of Law, Justice and Parliamentary Affairs 29 BLD 3 (2016) the government has enacted the Children Act, 2013 (Chowdhury. \& Fahim, 2019). But due to lack of proper identifying measures, counseling and planning to rehabilitate the delinquent juveniles all efforts has failed (Ferdousi, 2013). To ensure the future development of the country by protecting the youth generation from delinquency, juvenile delinquencies have to be control through proper initiatives.

\section{Meaning of Juvenile Delinquency}

The term 'juvenile delinquency' is composed of the words juvenile and delinquency. Juvenile means a child who has not attained the age of majority according to the law to which he or she is a subject or the child who has not attained an age at which he or she like a major under the law can be held liable for his or her felonious activities or the person who is not measured as sufficient matured both physically and mentally to understand the nature and consequences of his or her own activities. Delinquency means antisocial activities or those activities which do not permit by the existing laws of the country or not obeying the rules and regulations of the country or involve in criminal activities. "The term delinquency has been derived from the Latin world 'delinquer' meaning to 'omit'. The 
Roman used the term to refer the failure of a person in case of performing assigned duty or task. It was in 1484 when William Coxton used the term 'delinquent' to describe a person found guilty of customary offence. The word also found place in the famous Shakespearean play 'Macbeth' in the year 1605. Indeed, in ordinary sense, delinquency is a form of behavior or rather misbehavior or deviation from the commonly accepted norms or conduct in the society" (Chingtham, 2015). It refers those behaviors of children and adolescents which do not approve the country and for which there is a provision of punishment for public interest. It also covers antagonistic and disobedient behavior of adolescents and their malignant attitude towards society. When any criminal activity is committed by an adolescent i.e. who has not attained the age of eighteen years is treated as juvenile delinquency. Simply, participating in any illegal behavior or committing any act forbidden by the law of the country by an adolescent is called juvenile delinquency and the adolescent is called delinquent. Sometime some non-criminal activities of adolescents are also treated as juvenile delinquency which will not be treated as crime if committed by an adult like leave home without permission of the parents, smoking (Phogat, 2017).

"A child can be considered as delinquent only when it becomes necessary to take legal steps for the tendency of his antisocial behavior. According to the definition of Criminologist Ferdinand 'the failure of the children to show expected behavior to the society is called juvenile delinquency" (Chowdhury. \& Fahim, 2019). Delinquent children belong to that category of exceptional children who show considerable digression in terms of their social adjustment and are consequently also labeled as socially deviant. They violate social norms and values which are threat for the maintenance of peace in the society and which if not control properly in time may turn into potential offenders.

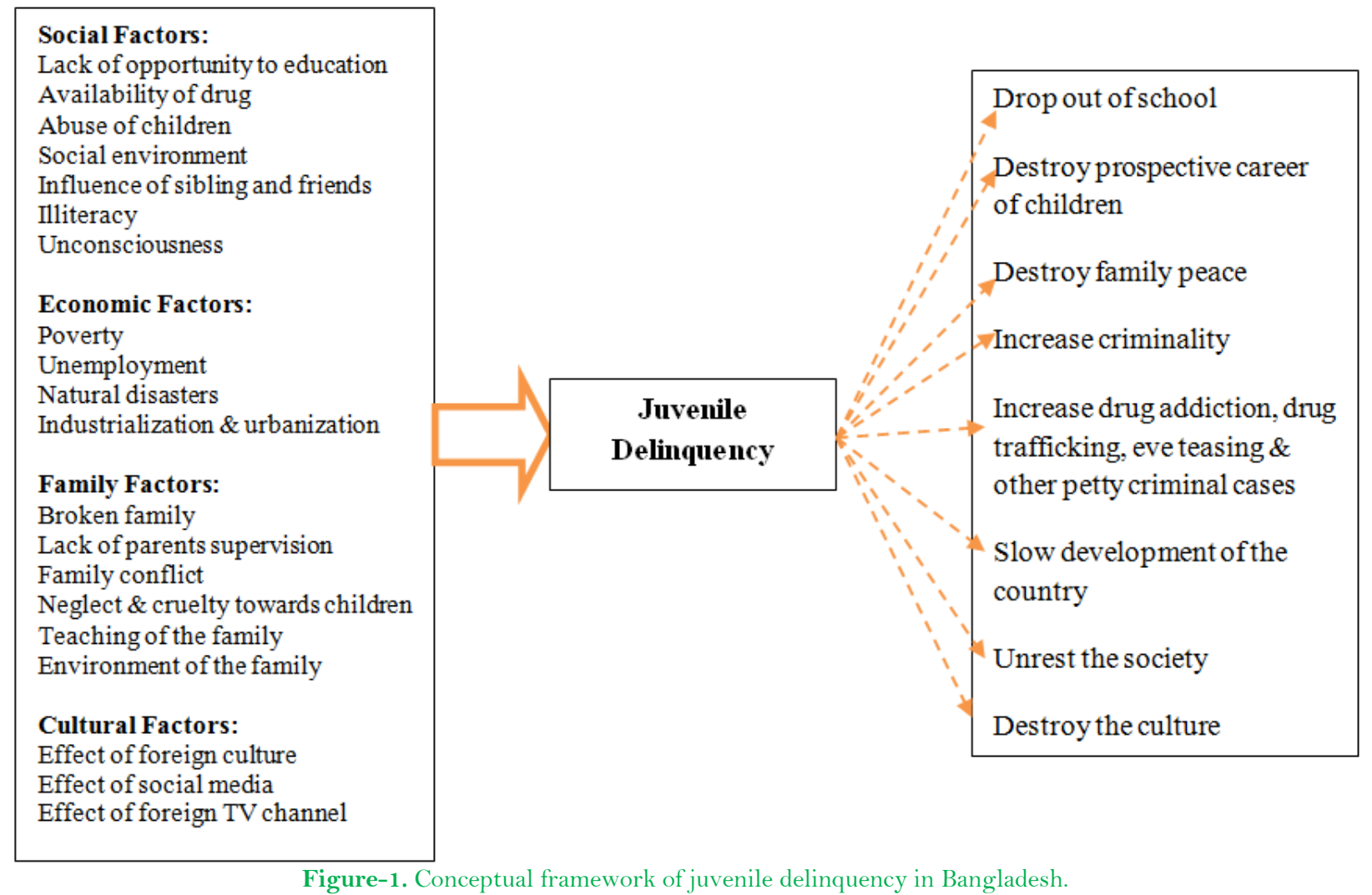

Figure 1 shows various factors of causing juvenile delinquency in Bangladesh and its consequences.

\section{Socio-Economic, Cultural and Family Factors Causing Juvenile Delinquency in Bangladesh}

The trend of juvenile delinquency exists from the very beginning of human civilization. Its rate is not same in countries of the world. It may be different from state to state or form society to society due to the difference of socio-economic condition, culture, environment and family pattern. In Bangladesh juvenile delinquency exists from the very beginning of the establishment of the country but currently it has reached in such a level that it is a matter of great concern for the country. The different socio-economic, cultural and family factors causing juvenile delinquency in Bangladesh are discussed below:

\subsection{Social Factors}

Society is that institution for a child which has significant role for the physical, mental and moral development of a child. It can also prevent a child from deviant. A child get first and primary teaching from the family and secondly from the society. "The social forces in the form of the social norms and values affect significantly the behavior of the child. Moral degradation, social deviance, immoral practices, others negative values and norms prevalent in the society are the negative impact on the attitude of the adolescents thereby contributing them to become delinquent" (Chingtham, 2015). When a child born with antisocial personality disorder normally he or she will be grow up in an abnormal environment which lead the child to deviate from social norms and values. A minor who is not intelligence enough or who is not mature enough cannot $\mathrm{j}$ udge what is good or bad for him and is influenced more by the prevailing bad practices or customs of the society and is in the high risk to involve in the delinquent activities. Various social factors contributing in the juvenile delinquency in Bangladesh are:

i. Lack of Opportunity of Education: Education and criminality has a connection i.e. where the rate of education is high criminality rate is low there and where the education rate is low criminality rate is high. Lack of opportunity of education is one of the leading factors causing juvenile delinquency in any 
society. The result of lack of opportunity of education may be extreme anxiety, frustration and idleness among children which encourage the teenager to involve in antisocial activities (Mwangangi, 2019). Lack of opportunity of education includes high cost of education, insufficient school or long distance from school, insufficient materials, abuse in the school, low quality of teaching and absent of teachers etc. Though the government of Bangladesh has declared free and compulsory education for all children but still a considerable portion of the children (street children, vagabond children, children staying in railway station, bus terminal and launch ferries, guardian less children) are out of this program. This portion of the children is a threat for the society and most of them are involved in various antisocial activities.

ii.

Drug Abuse and Availability of Drug: Drug abuse is one of the major contributing factors of causing juvenile delinquency in Bangladesh. It has negative impacts on children which causes deviation of children from social norms and values. Drug addiction give birth criminality in the society as the behavior of an drug addicted child is very desperate, he do not have common sense like intoxicated person and he is out of control of the family and to arrange money to buy drugs sometimes he physically torture the family members and involve in various criminal activities like theft, robbery and extortion etc. Drug addiction reduces cognitive ability of children, diminish their thinking capacity and limit their capacity for compromise and for rational dialogue (Mwangangi, 2019). Availability of drugs is also liable for increasing juvenile delinquency in the country. When drug is easily available soft minded innocent children without understanding the consequences addicted into drugs and sometimes some corrupted person involves in drug trafficking use the innocent children which ultimately causes juvenile delinquency. In Bangladesh still drug is available though the law enforcing agencies are trying their level best to abolish drug trafficking and illegal drug business from the country.

iii. Child Abuse and Cruelty Towards Children: "Child abuse is the deliberate attack on a child by a parent or other care givers which results into physical, psychological and emotional injuries” (Ojo, 2012). Cruelty towards the children makes them deviators, reckless and the neglected and abused children are at high risk to become delinquent at adolescence and become criminal adult (Ojo, 2012).

iv. Environment: Environment i.e. healthy and hygienic environment is one of the essential elements for the physical as well as mental development of a child. A considerable portion of children grow up in slum which is not healthy and hygienic and such living environment is not at all suitable for the physical development and mental growth of a child. Due to the shortage of land of the country sometimes people have to live in industrial area which is not good for health. Environment of industrial areas and slum of Bangladesh can never brings good lesson for juveniles and influence them to involve in criminal activities. Due to dirty, unhygienic and nasty environment in the slum and industrial areas of Bangladesh male as well as female delinquents are increasing rapidly which is an alarming for the country (Chowdhury. \& Fahim, 2019). If the residential area is healthy and hygienic, free from racket and crime and effective for the physical development and mental progress of the children, the rate of juvenile delinquency will be reduced dramatically.

v. Influence by Sibling and Friends: Younger siblings always influence by the older siblings and try to follow them. Older siblings who are involved in antisocial activities may easily draw their younger siblings into same kind of activities (Ojo, 2012). School is an institution where children from various family backgrounds meet, interact and influence one another. Sometimes due to mischief some children fails to acquire proper knowledge from school to build up their moral development and to increase their educational qualities and may eventually become delinquents due to the interaction of naughty children. Siblings' and friends' violence is an encouraging factor of juvenile delinquency in Bangladesh.

\subsection{Economic Factors}

Economic conditions play a vital role to increase juvenile delinquency in the society. Economic problem is still a big challenge for Bangladesh. Bangladesh is a developing country of the world which facing various problems but economic problem is the main problem in fact number one problem of the country. When a child does not get basic necessities from the family he become depressed, bored and frustrated which leads him to pick wrong way and involve in criminal activities (Chowdhury. \& Fahim, 2019). "If a child feels that he has no food to eat, and his ego is about to be tainted in the society, and his neighborhood is charming, so strong as compare to his family set up, here the teenage can feel the idea to get wealthy, so most of the time he chooses the wrong way because of an individual, it is impossible to be wealthy in a short time. In this condition, the person joins the gang group and become delinquent” (Alamgir et al., 2018). Various social factors contributing in the juvenile delinquency in Bangladesh are:

i. Poverty: Poverty is the root cause of social problems in Bangladesh. Poverty and delinquency is intimately connected. An area where poverty rate is high delinquency rate is also high there (Mwangangi, 2019). Inability of family to provide certain basic needs such as food, clothing, health and education has signification contribution in the juvenile delinquency (Birckhead, 2012). Due to extreme poverty many children in Bangladesh cannot complete even primary education and have to work to contribute financially in family. It increases child labor in the country. Child labor is one of the major factors that drive juvenile delinquency in Bangladesh (Chowdhury. \& Fahim, 2019). Most of the cases juvenile delinquents work hard (Islam, 2015) to lead their life and some of them are involve in heinous crime like robbery, extortion, hijacking, pick pocketing, smuggling and even commit murder (Chowdhury. \& Fahim, 2019).

ii. Unemployment: Another major problem in Bangladesh is unemployment. When active persons search for work but do not get due to shortage of employment problem in the country then they suffer from mental depression and frustration which creates social chaos and criminality in the society and the children of the family involve in criminal activities. When the parents especially father cannot fulfill the demand of the family and children then he cannot distinguish right and wrong rather he try to earn 
money in any way as a result sometimes he involve in illegal drug business and engage his family and children (Chowdhury. \& Fahim, 2019). Many families live in slum, near railway line as floating and industrial areas in Bangladesh involve in illegal activities especially drug trafficking and selling to earn their livelihood and engage their innocent children. Of course sometimes people having other opportunities involve in illegal activities and engage their family and children which not only create criminality in the society but also increase juvenile delinquency.

iii. Natural Disasters: Almost every year Bangladesh especially coastal areas have to face natural disasters which destroy many human lives, cattle, animals, crops and natural resources. Every year natural disasters like Cyclone (Sidr, Aila etc.), river erosion and collapse of mountains pauperize many families and getting no other ways people migrant from rural areas to urban areas to survive. Due to natural disaster people losing homeland and all wealth of the life become mendicant and to earn livelihood involve any activities without considering legal or illegal and also engage their teenage children which increase juvenile delinquency in Bangladesh. Moreover, children of these families are sometimes abused by some corrupt politicians.

\subsection{Cultural Factors}

Culture covers social behavior and norms of society as well as knowledge, beliefs, arts, laws, customs, capabilities and habits of the individuals live in the society. Culture of a society has influence on the children. If the culture of a society is good children achieve good things and if the culture is not good children cannot achieve good thing from that society. Due to industrialization, urbanization, change of family pattern, influence of social media like Facebook, WhatsApp, Instagram, imo and Indian TV channel many joint families of Bangladesh has broken and people want to live isolate as a result people leaving own culture follow some unjust foreign culture which has direct negative impact on children. Due to diminish of own culture and the impact of foreign bad culture many children in Bangladesh are getting involve in various criminal activities such as smoking, drug trafficking, drug business, snatching, extortion, robbery and massacre (Chowdhury. \& Fahim, 2019). Beside these, due to the influence of cinema and some bad movies and TV serials sometime many children try to practice antisocial activities which ultimately increase juvenile delinquency in the country. Illiteracy is another factor causing juvenile delinquency in Bangladesh. A considerable portion of the people of the country is illiterate and the illiterate people cannot realize the necessities of education in human life and most of the cases they are not serious rather incurious regarding education of their children as a result many children cannot continue their education more and dropped out of school. Most of the cases family cannot control these children and involve in antisocial activities which eventually increase criminality in the society.

\subsection{Family Factors}

Family is the first and best institution from where children learn their basic learning. For the physical, mental and moral development of a child the role of family is most important. Parents are not only the best teacher for their children but also an influential component to protect them from rising malfeasance (Miles, Kulesza, Ewing, Shih, \& Tucker, 2015). "Families serve several important functions within society, including socialization, economic support, nurturing, protection of vulnerable members and perpetuating the family grouping" (Patterson, 2002) and also provide physical and emotional security to the children along with their all other basic necessities (Mwangangi, 2019). Family protection is a recipe for the development of skills and talents, physical growth and cognitive and emotional development of children. The role of family is very significant to engraft norms and values within children (Mwenda, 2012) as if the attitude and behavior of the parents is antisocial their children hearten such behavior and attitudes to keep on into adulthood (Chaffin et al., 2004). Due to lack of proper family teaching, control and guidance juvenile delinquency is increasing in Bangladesh. Various family factors contributing in the juvenile delinquency in Bangladesh are:

i. $\quad$ Broken Family: Family broken is one of the major problems of Bangladesh. Recently it has increased in such a level that it is a matter of great concern for Bangladesh. Bridegroom, bride and offspring all are affected by family broken. It has many adverse effects on family, society, bride, bride groom and mainly on the offspring (Patoari, 2020). When a family is broken the women and her children become more vulnerable and they are not respected in society and even parental family of the women and the neglected children are inspired more in criminal activities. Family broken is linked with juvenile delinquency as children from broken families involve in juvenile delinquency more than the children from non broken families (Nourollah, Fatemeh, \& Farhad, 2015). When there is a stable marriage between parents children are able to enjoy the best preparation and advantages for the success and happiness of the life (Wardle, 2004). Parental divorce places the children at the high risk of criminality. The rate of unemployment, drop out of school and sexual violence and other antisocial activities is more among the children of broken families or one-parent families than non broken or two-parent families (Weijer, Thornberry, Bijleveld, \& Blokland, 2015).

In Bangladesh when a family is broken then most of the cases the children live with mother who has to face various problems including financial problem and when she got second marriage the children grow up under guidance of maternal or paternal relatives like grandmother, grandfather etc. and most cases due to proper care and guidance prospective career of the children destroy and they involve various antisocial activities like smoking, escape from school, drug addiction etc. which eventually increasing juvenile delinquency in the country. Recently in Bangladesh the rate of family broken has reached in extreme level and sometimes on flimsy ground many families are broken which creates various problem in the society like child labour, child trafficking, drug addiction, sexual violence which ultimately liable for increasing juvenile delinquency in the country.

ii. Lack of Parents Supervision: Parents are the best supervisors and guide of the children. To build a child as a successful man in life by proper education the monitoring, guidance, love, care, control and rule of parents are unlimited. Family is the primary enculturation agent for the children to develop 
their moral values and ethical standards (Kemme, Hanslmaier, \& Pfeiffer, 2014) and if the family cannot play proper role they may be deviated. Day by day in Bangladesh women are being educated and with men they are involving in economic activities more(Patoari., 2020) especially in garments sector as a result they have to stay most of the time of the day out of the house and cannot look after their children properly and due to lack of proper monitor and supervision children of these families involve various antisocial activities which ultimately increasing juvenile delinquency in the country.

iii. Parents Conflict: Parents conflict is another family factor increasing juvenile delinquency in Bangladesh. Conflict between husband and wife not only lead to nuptial breakdown but also parents' loss of love, care and affection and emotional avoidance of their children (Alnasir \& Al-Falaji, 2016). Children from the families having conflict between their parent are more troublesome and delinquent and more than ninety percent of the delinquents from unhappy families (Ojo, 2012). Due to various social, economic and cultural reasons day by day tolerance level between husband and wife in Bangladesh is decreasing which is one the key factors of family conflict in Bangladesh. If there is a conflict between parents children suffer from depression, frustration and become uncontrolled and due to frustration they involve in immoral activities which increasing juvenile delinquency in the country day by day.

iv. Cruelty towards Children: Mind of the children is very soft and they easily imitate anything. Family member especially parents are the best friends of a child. Family environment and behavior of the parents have impact on children. To develop healthy personality of children love, care, affection, good behavior and positive family environment is pre requisite and in the absence of which they may be acrimonious, fretful and may revolt against parents, escape from family and as a result involve in various criminal activities (Mwangangi, 2019). Children having experience of mistreatment, neglect, rejection and abuse by the parents and family members are at high risk of involving delinquency (Ryan, Williams, \& Courtney, 2013).Many parents in Bangladesh are illiterate and incognizant do not know how to treat the children. Due to rude behave and cruelty many children in Bangladesh deviate from social norms and rules.

\section{Consequences of Juvenile Delinquency in Bangladesh}

Juvenile delinquency is one of the major problems in Bangladesh. It has various negative impacts on the delinquents, family of the delinquents, society and country. Almost 550,000 children in the country are drug addicted (Noman, 2018) and about thirty percent $(30 \%)$ of them are involved in various criminal activities to manage money to buy drugs (Khan \& Tipu, 2016). The juvenile delinquency in Bangladesh in such a level that it has already become a matter of great concern of the country and if it is not control by proper initiatives the country have to pay high price for it. "Around $44 \%$ of the street children in the country are involved in drug peddling, $35 \%$ are involved in picketing, $12 \%$ in mugging, $11 \%$ in human trafficking and $21 \%$ in other criminal activities" (Khan \& Tipu, 2016). The consequences of juvenile delinquency in Bangladesh are:

\subsection{Drop out of School and Destroy Prospective Career of Children}

The first sufferer of juvenile delinquency is the delinquent himself. When a child involve in juvenile delinquency it causes mental distortion of the child and he cannot continue his study more as a result he drops out of school which ultimately destroy the prospective career of the child and also destroy the dream, hopes and aspiration of the family regarding him. Due to juvenile delinquency, hard labor of many parents going in vain and the children do not become asset rather become burden of the family and society.

\subsection{Destroy the Peace of the Family:}

When a child becomes delinquent he does not follow the rules, regulations and guidance of the family. He leads unsystematic life and family or society cannot control him. Due to his promiscuous life delinquent child creates various problems in the family and sometimes physically torture family members and even parents which not only destroy the peace of the family but also destroy the reputation of the family and people belittle the family members.

\subsection{Increase Criminality}

Juvenile delinquency is the root of adult criminality. Due to juvenile delinquency children at their adult age become heinous offender. Juvenile delinquency in Bangladesh is increasing various criminal activities in the country and sometimes children are committing heinous crimes like "Oishee Rahman, a 17 year old girl who killed her parents, police inspector MahfuzurRahman and SwapnaRahman on $18^{\text {th }}$ August 2013, when her parents had taken her mobile phone" (Patoari, 2020) and for this murder trial court sentenced to death penalty to Oishee Rahman but the High Court Division of Bangladesh Supreme Court commuted her sentence to life imprisonment (Chowdhury. \& Fahim, 2019). Another one is Tasfia murder case. Tasfia, a student of class ix of Sunshine Grammar School and College, Chittagong, age 16 years who went on a date with her boyfriend Adnan Mirza, a student of class ix of Bangladesh Elementary School on May 01, 2018 and on May 02, 2018 her dead body was found at the Naval Road area, Chattogram (Chowdhury. \& Fahim, 2019). Father of the victim filed a case against six accused including main accused her boyfriend Adnan Mirza. The victim and her boyfriend introduced each other through social media. In Chattogram Metropolitan Area many gangs of juvenile involved in various criminal activities (Chowdhury. \& Fahim, 2019).

\subsection{Increase Drug Addiction and Drug Trafficking}

Drug addiction, drug trafficking and illegal business of drug is a problem in Bangladesh. Though the government is zero tolerance in this regard and the law enforcing agencies are frequently performing successful operation to eradicate illegal drug business and drug trafficking still it is available which is destroying the youth generation of the country. Delinquent juveniles of the country are mostly involved in drug addiction and drug trafficking. 


\subsection{Slow Overall Development of the Country}

Juvenile delinquency is an obstacle in the development of the country. When the youth generation of a country is involved in antisocial activities they cannot play proper role for the social progress and economic, cultural and educational development of the country. Delinquent children cannot become human resources rather becomes a burden of the country and involve in various antisocial activities. If the young generation of a country cannot become successful men in life by acquiring proper knowledge and education they never can give good thing to the country which ultimately slow overall development of the country.

\subsection{Destroy the Culture}

Juvenile delinquency also destroys the culture of a country. Delinquent juveniles do not follow rules, regulation, social norms and customs of the country. As they are disobedient they do not religious direction and they lead their life as they like. By avoiding the existing customs, culture, social norms they practice outlandish customs and culture which ultimately destroy the culture of the country. They also do not follow the religious directions.

\section{Juvenile Delinquency and Laws of Bangladesh}

To govern the juvenile justice system in Bangladesh there is no separate law (Chowdhury. \& Fahim, 2019). Beside the constitution of Bangladesh, parliament enacted a law immediately after the independence of the country known as the Children Act, 1974 which was the fundamental law to deal with children. In 2013 Bangladesh enacted a new law known the Shishu Ain 2013 (The Children Act, 2013) to implement the United Nations Convention on the Rights of Children and the new law repeal the Children Act, 1974. This new law is the fundamental law in Bangladesh "dealing with children rights, delinquent children, their correction mechanism and separate justice system from adult offenders” (Chowdhury. \& Fahim, 2019).

\subsection{Constitution of the People's Republic of Bangladesh}

Constitution as the supreme law of the country protected all citizen form any kinds of discrimination, injustice and cruelty. Article 15 of the constitution imposed duty on state to take appropriate measures to ensure social security of the citizens and article 17 imposed duty on the state to adopt effective measures to ensure free and compulsory education for all citizen. All are equal before law, equal opportunity for all and right to protection of law has ensured under article 27, 19 and 31 . Article 28 has given authority to the state to adopt special provision in favor of women, children and backward section of citizens. Fundamental rights have guaranteed under part-III i.e. from article 26 to $47 \mathrm{~A}$. Article 44 has given right to the citizens to enforce their fundamental rights through article 102 of the constitution when their fundamental rights are violated.

\subsection{The Children Act, 2013}

The Children Act, 2013 section 4 define that all persons who has not attained 18 (eighteen) years shall be treated as children. The government shall appoint in every district, upazilla and metropolitan area one or more probation officers who shall (where applicable) meet with children and shall provide assurance of all sorts of facilitation if a child is brought to the police station and shall identify the reason of bringing of police station and finds out the parents or other guardian of the children. The government shall establish Children Welfare Board at national, district and upazill level under the supervision of the Ministry of Social Welfare and Children Affairs Desk shall be set up in all police stations to maintain separate registration of children case and to inform the probation officer, parents or other guardian of the children and also to take necessary steps for all basic needs including medical assistance if necessary. There shall be at least one or more children's court in every district headquarter which shall composed of by an additional district judge to try the offences committed by any child and the court shall have same power and perform same jurisdiction like session court and if there is no children's court in any district, district and session judge shall discharge the duties of Children's Court in addition to his normal duties. The room or building of the children's court shall be separate and at the time of trial of a child no lawyer, police or court staffs can wear their official uniform and the court shall consider the age, character, socio-cultural and family background of the children.

Any child below 9 (nine) years can never be arrested or detained. When a child is arrested, the police officer executing the arrest shall immediately inform the children affairs police officer the causes and place of arrest, the allegation brought against the child and shall record in file the age of the child and after arrest no child shall be hand-cuffed or tied up with rope or cord around the waist. The concern officer shall inform immediately to the parents or other legal guardian of the child, the probation officer and the nearest board (in case of necessity) regarding the arrest. In case of any investigation under this act the provision of the Code of Criminal Procedure, 1898 shall be applicable so far as possible. The parents or legal guardian of the children and the probation officer or the social worker shall remain present during the record of the statement of the children by the children affairs police. For the better interest of the children or to settle the dispute, after arrest or detention of a child, diversion may be undertaken at any stage of the proceeding instead of formal trial.

Whatever stated in any other law for the time being enforce or the Code of Criminal Procedure, 1898 or other section of this act, after the arrest of any child if it is not possible to release the child or send him to diversion or produce before the court, the children affairs police may release him on bail with or without surety to the custody of the parents or other legal guardian of the child or the probation officer and in this regard it will not be considered whether the offence is bailable or non-bailable. When a child is produce before children's court, the court may release him on bail or order to detain in Safe Home or Children Development Centre. Without legal representation on behalf of the child, no children's court shall try any case to which a child is connected and in every hearing the lawyer of the child mandatorily shall remain present and if the lawyer is unable to conduct the case, the proceeding of the case shall remain postpone until new lawyer is appointed. The government shall establish and maintain required number of Children Development Centers, based gender disaggregation for accommodation, correction and development of the children ordered to be detained in judicial proceedings and for 
the children under trial. The act also contained provision of punishment for special offences in respect of children which may be up to 5 (five) years or fine up to 1 (one) lac taka or both.

\subsection{The Code of Criminal Procedure, 1898}

The Code of Criminal Procedure, 1898 creates an obstruction in the way of joint trial of juvenile and adult offenders (Noman, 2018). Section 29B states all offences other than offence punishable with death or imprisonment for life is committed by any person who has not attained 15 (fifteen) years may be tried by Chief Judicial Magistrate or Chief Metropolitan Magistrate or any Magistrate specially by the government. According to section 392 in case of infliction of whipping on a person who has not attained 16 (sixteen) years the instruments, mode of infliction and the part of the body of that person for infliction shall be determined by the government. Section 399 if any criminal court sentenced imprisonment for any offence to a person who has not attained 15 (fifteen) years, the court may order to confine the offender in reformatory centre instead of being imprisoned in criminal jail. Section 497 empowered the court that in case of non-bailable offence, the court may grant bail if the accused is under 16 (sixteen) years to a woman or sick or infirm person.

\subsection{The Penal Code, 1860}

According to section 82 whatever done by a child who has not attained 9 (nine) years, is not an offence and section 83 states "Nothing is an offence which is done by a child above nine years of age and under twelve, who has not attained sufficient maturity of understanding to judge of the nature and consequences of his conduct on that occasion".

\section{Way Out}

The future development of a nation is completely depends on it children. If the children are deviated ultimately it destroys the whole nation. A considerable portion of total population of Bangladesh is children and day by day juvenile delinquency is becoming an alarming issue of the country. As the juvenile delinquency is the root of adult criminality, so if the juvenile delinquency is not prevented in Bangladesh timely by proper initiatives it will destroy the youth generation of the country. The juvenile delinquency in Bangladesh can be prevented by taking the following measures:

i. $\quad$ Free and Compulsory Education: Though the government of Bangladesh has declared free and compulsory primary education for all children and working very hard to success this program but still a considerable portion of the children especially the street children are out of this program. Government is supplying free text book up to secondary level and giving various stipend. But it is not sufficient to ensure education of all children of the country. The educational materials are very expensive which poor people cannot afford. The government should increase allocation in national budget in education sector and have to give subsidy in educational materials. To include all the children of the country in free and compulsory education program government should give stipend especially to the children of the poor family and street children and have to create awareness among them and monitor properly so that not a single child is deprive from education. If the government can ensure free and compulsory education for all children of the country up to higher secondary level, juvenile delinquency will be reduced dramatically in the country.

ii. Control of Drug Abuse and Drug Trafficking: Control of drug abuse and drug trafficking is a big challenge for Bangladesh. To eliminate juvenile delinquency form the country there is no alternative of control of drug abuse and drug trafficking. Street children, orphan, children from poor family and children from broken family are mostly involve in juvenile delinquency and in the long run become habitual offender. To control drug abuse and drug trafficking government should implement the existing laws rigidly and have to create massive awareness among the people and in this regard beside the government NGOs, print and electronic media can play a vital role.

iii. Elimination of Poverty: Poverty is linked with juvenile delinquency and to control juvenile delinquency in Bangladesh poverty should be eliminated by proper initiatives. To eliminate the poverty government should encourage small and medium entrepreneurs and for this reason loan should be given to the young and energetic people on easy term and low rate of interest and should give special allocation for the people living under poverty line and there must have proper management of the allocation. To remove unemployment problem new job opportunity should be created and the government should encourage the people on work-oriented education. Training should be given to the educated young and energetic people on various practical matters and after completion of training they should be given loan on easy term and low rate of interest.

iv. Avoid Family Conflict: As family conflict is directly liable for juvenile delinquency to reduce juvenile delinquency parents should avoid family conflict. Due to various reasons family conflict has increased in Bangladesh which directly increasing juvenile delinquency in the country. Before involving family conflict or taking any decision like divorce or separation parents should think regarding the future of their children. Both the parents have to avoid their ego problem and have to increase their tolerance level and should sacrifice many things only considering the vulnerability of the life of their children.

v. Increase Family Supervision: Lack of supervision of the family is liable for juvenile delinquency in Bangladesh in many cases. Parents especially illiterate and unconscious and where both of the parents are working cannot supervise their children properly. Parents have to care and supervise their children properly especially they have to take care where their children are going, when they are coming home, where and with whom they are passing their time and who are the friends of their children.

vi. Proper Natural Disaster Management: There must have sufficient allocation in national budget for the people affected by the natural disaster especially to resettle the people who become pauper by losing all wealth of the life due to natural disaster like cyclone (Sidr, Aila etc.). There must have effective national disaster management which shall be composed of efficient and expert people. 
vii. Avoidance of Foreign Culture: Foreign culture especially Indian TV channel and various social media are also liable to increase family conflict and juvenile delinquency in Bangladesh. Government should control strictly foreign TV channel and the parents must care so that their children are not addicted in social media.

viii. Proper Implementation of the Children Act, 2013: Though the government enacted the Children Act, 2013 by abolishing the old law i.e. the Children Act, 1974 but still it is not completely implemented. Government must fulfill the requirements of the act i.e. must be established "children affairs desk" in all the police station of the country headed by a child affairs police officer, appoint the probation officer, sufficient number of juvenile court, safe home, children development centre.

ix. Social Awareness: Social awareness program must be introduced among the children and illiterate and unconscious parents regarding the negative impacts of juvenile delinquency as well as drug addiction, addiction of social media and foreign culture. Moreover, parents and other family members, society and the country have to be more conscious and concerned about the teenagers.

\section{Conclusion}

Juvenile delinquency is a common phenomenon in many countries of the world. But due to variation of social, economic, cultural, educational, religious teaching, family conflict, law and order situation of the country, environment and political situation the rate of juvenile delinquency is different from state to state. In a developing country like Bangladesh which is one of the densely populated countries of the world, juvenile delinquency rate is normally higher than many countries. Due to poverty, illiteracy, lack of awareness, drug trafficking and availability of drug, unemployment, natural disaster, high rate of family conflict and divorce, lack of supervision of parents, cruelty towards children, avoidance of religious direction, effect of foreign culture and social media, the rate of juvenile delinquency in Bangladesh has reached in such a level that it has become a matter of great concern. Moreover, due to urbanization and industrialization day by day the rate of juvenile delinquency is increasing rapidly in the country which deviate the attention of the youth generation of the country from their main task i.e. education, healthcare, sports, cultural activities, religious teaching, social and humanitarian activities. As there is rapid revolutionary biological as well as emotional changes, the period of juvenility is full of anxieties, worries, variances and complications and as their mental faculties are not mature enough cannot take the right decision in life and frequently involve in anti-social activities and become delinquent. As one of the root causes of adult criminality is juvenile delinquency, it is a matter of great concern for Bangladesh because at present a considerable portion of total children are involve in various criminal activities like drug addiction, drug trafficking, picketing, arms trafficking, human trafficking, eve-teasing and other petty criminal activities. Some of them are involve more heinous offences like sexual violence, political violence, extortion, robbery, kidnapping, acid throwing and murder. Juvenile delinquency has various negative impacts on the delinquents, family, society and country. It destroys the prospective career of a child, destroys family peace, increases drug addiction, drug trafficking and other criminal activities in the society, destroys overall development of the country and creates unrest in the family and society. In Bangladesh children from poor families as well as rich and aristocratic families are involved in criminal activities. To get relief from this anathema and to protect the young generation of the country the above mentioned measures should be taken immediately and in this regard beside the government NGOs, civil societies, print and electronic media, educational and religious institutions can play a vital role.

\section{References}

Ahmad, R. (2017). Theory and practice of criminology: Bangladesh Perspective (2nd ed.). Dhaka, Bangladesh: University Publications.

Alamgir, M., Rahim, W., \& Ali, M. Z. (2018). Explore the factors behind juvenile delinquency in Pakistan: A research conduct in Juvenile Jail of Rawalpindi, Pakistan. International Journal of Scientific and Engineering, 9(3), 1086-1091.

Alnasir, F. A., \& Al-Falaji, A. A. (2016). Factors affecting juvenile delinquency in Bahrain. Journal of General Practice, 4(1), 1-5.Available at: http://dx.doi.org/10.4172/2329-9126.1000229.

Birckhead, T. R. (2012). Delinquent by reason of poverty. Washington University Journal of Law and Policy, 38, 53-107.

Chaffin, M., Silovsky, J. F., Funderburk, B., Valle, L. A., Brestan, E. V., Balachova, T., . . Bonner, B. L. (2004). Parent-child interaction therapy with physically abusive parents: Efficacy for reducing future abuse reports. Journal of Consulting and Clinical Psychology, 72(3), 500-510.Available at: https://doi.org/10.1037/0022-006X.72.3.500.

Chingtham, T. (2015). Causes of juvenile delinquency in the higher secondary school students. IOSR Journal of Research and Method in Education, 5(5), 20-24.Available at: 10.9790/7388-05522024.

Chowdhury, I. A., Khan, M. M., \& Uddin, I. (2012). Causes and consequences of Juvenile delinquency in Bangladesh: A sociological analysis. International Journal of Social Science Tomorrow, 4(1), 1-11.

Chowdhury., M. A. A., \& Fahim, M. H. K. (2019). An appraisal of causes and consequences of Juvenile delinquency in Bangladesh: Search for a durable solution. Bangladesh Institute of Legal Development (BiLD) Law Journal, 4(1), 60—80.

Ferdousi, N. (2013). Juvenile justice for the best interest of the children in Bangladesh: A legal analysis. Journal of Law, Policy and Globalization, 18, 22-32.

Hoeve, M., Dubas, J. S., Eichelsheim, V. I., Van der Laan, P. H., Smeenk, W., \& Gerris, J. R. (2009). The relationship between parenting and delinquency: A meta-analysis. Journal of Abnormal Child Psychology, 37(6), 749-775.

Islam, M. T. (2015). Juvenile delinquency in Bangladesh: Identifying the causes with reference to some case studies Law Journal Bangladesh, $2,6-12$.

Kemme, S., Hanslmaier, M., \& Pfeiffer, C. (2014). Experience of parental corporal punishment in childhood and adolescence and its effect on punitiveness. Journal of Family Violence, 29, 129-142.Available at: 10.1007/s 10896-013-9564-3.

Khan, M. J., \& Tipu, M. S. (2016). Children's involvement in crime on rise. The Dhaka Tribune, Dated: October 1, 2016.

Mehtab, F. H. (2008). Juvenile justice system of USA and Bangladesh: A comparative study of diversion and alternative measures and hard realities of Juvenile Justice system in Bangladesh. Dhaka University Journal of Law, 19(1), 53-87.

Miles, J. N., Kulesza, M., Ewing, B., Shih, R. A., \& Tucker, J. S. (2015). Moderated mediation analysis: An illustration using the association of gender with delinquency and mental health. Journal of Criminal Psychology, 5(2), 99-123.Available at: 10.1 108/JCP-02-2015-0010.

Mwangangi, R. K. (2019). The role of family dealing with juvenile delinquency. Open Journal of Social Sciences, 7(3), 52-63.Available at: https://doi.org/10.4236/jss.2019.73004.

Mwenda, N. (2012). Introduction: Parents' involvement in children's lives in Africa. Africa Development, 37(3), 1-18.

Noman, S. (2018). Treatment of Juvenile delinquency under the criminal justice system in Bangladesh: An overview. Bangladesh Institute of Legal Development (BiLD) Law Journal, 3(2), 53-81.

Nourollah, M., Fatemeh, M., \& Farhad, J. (2015). A study of factors affecting juvenile delinquency Biomedical \& Pharmacology Journal, 5, 25-30.Available at: http://dx.doi.org/10.13005/bpj/551. 
Ojo, M. O. (2012). A sociological review of issues on juvenile delinquency. The Journal of International Social Research, 5(2 1), 468-482.

Patoari, M. M. H. (2020). Causes and effects of child marriage in Bangladesh: A case study at halishahar, Chattogram, Bangladesh. Academic Journal of Interdisciplinary Studies, 9(2), 162--172.Available at: https://doi.org/10.36941/ajis-2020-0034.

Patoari., M. M. H. (2020). Socio-economic and cultural causes and effects of increasing divorce rate by women in Bangladesh: A critical analysis. Asian Journal of Social Science Studies, 5(1), 21-31.Available at: https://doi.org/10.20849/ajsss.v5i1.713.

Patterson, J. M. (2002). Understanding family resilience. Journal of Clinical Psychology, 58(3), 233—246.Available at: 10.1002/jclp.10019.

Phogat, K. (2017). Juvenile delinquency in India: Causes and prevention Journal of Advances and Scholarly Researches in Allied Education, 13(1), $62-67$.

Rathinabalan, I., \& Naaraayan, S. A. (2017). Effect of family factors on juvenile delinquency International Journal of Contemporary Pediatrics, 4(6), 2079-2082.Available at: http://dx.doi.org/10.18203/2349-3291.ijcp20174735.

Ryan, J. P., Williams, A. B., \& Courtney, M. E. (2013). Adolescent neglect, juvenile delinquency and the risk of recidivism. Journal of Youth and Adolescence, 42(2), 454-465.Available at: 10.1007/s 10964-013-9906-8.

Wardle, L. D. (2004). Children and the future of marriage. Regent University law Review, 17(2), 279-310.

Weijer, S. G. A., Thornberry, T., Bijleveld, C. C. J. H., \& Blokland, A. A. J. (2015). The effects of parental divorce on the intergenerational transmission of crime. Societies, 5(1), 89-108.Available at: https://doi.org/10.3390/soc5010089. 